\title{
Immunohistochemical Expression of Epidermal Growth Factor Receptor in Different Histopathological Grades of Muco-epidermoid Carcinoma of Salivary Glands
}

\author{
Zainab Niazi ${ }^{1}$, Shoaib Naiyar Hashmi ${ }^{2}$, Saadia Muneer ${ }^{3}$ \\ ${ }^{1}$ Asistant Professor, Department of Oral Pathology, Islamabad Medical and Dental College, Saheed Zulficar Ali Bhutto Medical \\ University, Islamabad. \\ ${ }^{2}$ Consultant Histopathologist, Department of Histopathologist, Armed Forces Institute of Pathology, Rawalpindi. \\ ${ }_{3}^{3}$ Asistant Professor, Department of Oral Pathology, Islamabad Medical and Dental College, Saheed Zulfiqar Ali Bhutto Medical \\ University, Islamabad
}

\begin{abstract}
A BSTRACT
Objective: To determine the immunohistochemical expression of Epidermal Growth Factor Receptor (EGFR) in different histopathological grades of mucoepidermoid carcinoma (MEC) in salivary glands.

Patients and Methods: This cross-sectional study was conducted from August 2015 to September 2016 at Armed Forces Institte of Patholgy Rawalpindi (AFIP), to determine the immunohistochemical expression of Epidermal Growth Factor Receptor (EGFR) in different histopathological grades of mucoepidermoid carcinoma (MEC) in salivary glands. Thirty cases of MEC were retrieved from record files along with their paraffin blocks at AFIP, Rawalpindi. New histological diagnosis was made on freshly prepared Hematoxylin and Eosins section followed by application and analysis by immunostaining. Chi-square test was used to find the effect of EGFR on different grades of MEC.

Results: Out of 30 cases, 24 cases were positive for EGFR. In case of low-grade mucoepidermoid carcinoma, 8 cases were weak positive, whereas remaining six were negative. Out of eight cases of intermediate grade mucoepidermoid carcinoma, 3 were week positive, whereas remaining five are strong positive. In high grade mucoepidermoid out of eight cases seven were strong positive. P-value for EGFR was calculated as .036. EGFR expression increased with increase in grade of tumor.

Conclusion: The expression of EGFR increased with increase in grade of tumor.

Key words: EGFR, Mucoepidermoid carcinoma, Salivary Glands

Author's Contribution

${ }^{1-2}$ Conception, synthesis, planning of research and manuscript writing

Interpretation and discussion

${ }^{3}$ Data analysis, interpretation and

manuscript writing, Active participation in data collection.
\end{abstract}

Cite this article. Niazi Z, Hashmi SN, Muneer S. Immunohistochemical Expression of

Epidermal Growth Factor Receptor in Different Histopathological Grades of Muco-epidermoid

Carcinoma of Salivary Glands. JIMDC.2018; 7(4): 231-234

\section{Introduction}

Tumors of salivary glands have an important place in oral and maxillofacial pathology, having incidence of $5 \%$ around world. ${ }^{1}$ Mucoepidermoid carcinoma (MEC) is the most common malignant tumor of salivary glands, accounting for $15.3 \%$ of all tumors and $56.9 \%$ of malignant tumors.$^{2}$ This tumor is composed of three intermixed type of cells: mucin-producing cells, intermediate cells or clear cells, and squamoid cells. ${ }^{3}$ Mucoepidermoid carcinoma shows a variety of biological behavior that is correlated with histopathological grades of 
tumor. ${ }^{4}$ All treatment plans are based exclusively on histopathological grades. Number of microscopic grading systems based on specific microscopic parameters have been described to find the grades of mucoepidermoid carcinoma. ${ }^{5}$ EGFR is a "tyrosine kinase receptor" of ErbB family. EGFR is a membrane glycoprotein and has an extracellular ligand -binding domain, a transmembrane lipophilic part and an intracellular protein kinase domain. EGFR is present on chromosome 7p12 and in many types of cancers. It is involved in proliferation, angiogenesis and metastasis of cancer cells. EGFR encodes membrane glycoprotein that is activated by phosphorylation. ${ }^{6-8}$

In many cases of MEC of salivary glands, EGFR protein is strongly expressed. ${ }^{9}$ In high grade of MEC, the oncogenic glycoprotein MUC1 is greatly expressed..$^{10}$ MUC1 react with EGFR and cause activation of MAPK in mouse model. In MEC of salivary glands, ERK1/2 MAPKs expression is high in high grade MEC.

\section{Patients and Methods}

This cross-sectional study was conducted from August 2015 to September 2016 The study included thirty cases of mucoepidermoid carcinoma. The data was collected from clinical histories given with each case. Blocks were cut and stained with Hematoxylin and Eosin stains. Necrosed, scanty and autolysed tissue samples were excluded. After diagnosing on microscopy, histopathological grading was done according to Auclair et al and Goode criteria. ${ }^{11,12}$

Expression of EGFR on different grades of MEC was calculated by evaluating the percent of positive stained cells under the objective lens of power 40 with microscope. ${ }^{12}$ Positive staining appeared as a linear to finely granular pattern in cell membrane and adjacent cytoplasm. Chi-square test was used to find out the association of EGFR with different grades of tumor. P value $>0.05$ was taken as significant

\section{Results}

Among 30 cases, 23 patients were males and remaining 7 were females. Anatomically, 22 patients had tumor in parotid glands, while 4 had in submandibular areas. Other tumors were in palate, retromolor area, and in posterior $1 / 3$ of tongue. Most of patients had age between 40 to 60 years.
Immunohistochemical labeling patter:EGFR was applied to all 30 cases of Mucoepidermoid carcinoma. Both membranous and cytoplasmic stainings were considered. Among thirty cases eight cases were negative (-), while 24 were positive. Out of 24 positive 16 were weak positive $(+)$, while 8 were strong positive $(++)$. The low grade MEC was diagnosed in 14 cases, out of these 6 cases were negatively stained (-) and remaining 8 were weak positive $(+)$. In intermediate grade

MEC, 3 cases were weak positive $(+)$ while 5 cases were strong positive $(62.5 \%)$, where as in high grade MEC one case was weak positive (12.5\%) while the rest 7 were strong positive (87.5\%) Chi-square test was applied to evaluate the association of EGFR and grades of tumor. $P$ value of .036 was calculated and was significant. (Table 3).

\begin{tabular}{|l|l|}
\hline \multicolumn{2}{|c|}{ Table 1: Scoring System } \\
\hline Intra cystic component $<20 \%$ & 2 Points \\
\hline Neural invasion present & 2 Points \\
\hline Necrosis & 2 Points \\
\hline Mitosis (4 or more per 10 HPF) & 3 Points \\
\hline Anaplasia & 4 Points \\
\hline The quantitative grading system by these scores is: \\
\hline Low grade & 0-4points \\
\hline Intermediate grade & 5-6points \\
\hline High grade & 7-14points \\
\hline
\end{tabular}

Table 2:Score Assessment of Immunoreactions

\begin{tabular}{|l|l|}
\hline Score & Assessment \\
\hline Negative & $<5 \%$ of positive cells \\
\hline Week positive & $5-50 \%$ of positive cells \\
\hline Strong positive & $>50 \%$ of positive score \\
\hline
\end{tabular}

Table 3: Expression of EGFR in different grades of
tumors




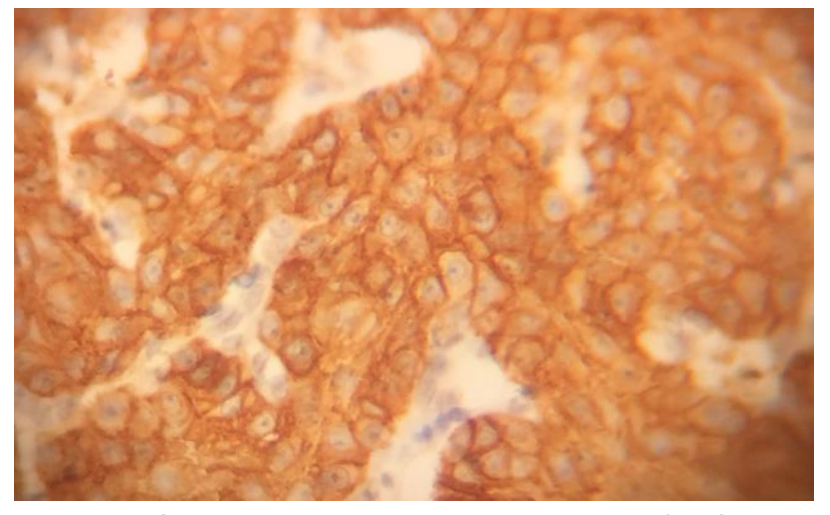

igure 1: Strong membranous positivity of EGFR in High grade Mucoepidermoid carcinoma (40x100)

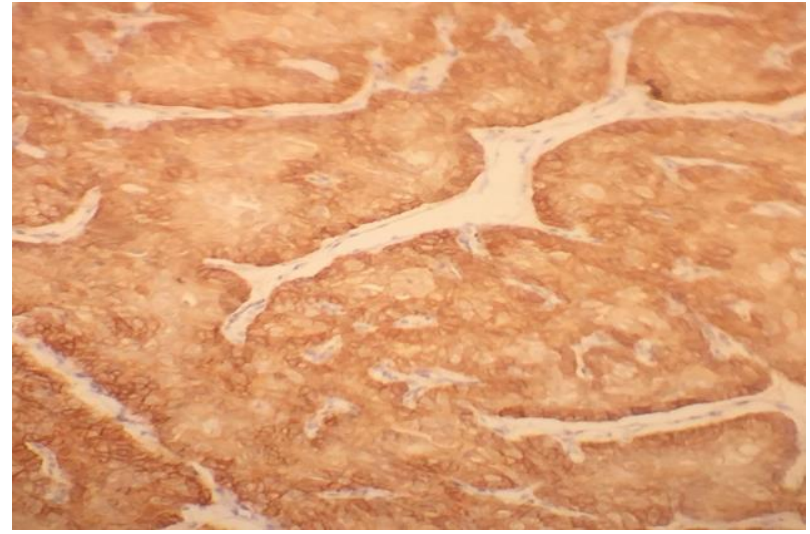

Figure: 2 High membranous positivity of EGFR in High grade MEC (10x10 Magnification)

\section{Discussion}

The EGFR/ErbB1 is a gene located on chromosome 7p12. This gene encodes membrane glycoprotein that is activated by phosphorylation. This activation induces a downstream signalling transduction cascade. ${ }^{13}$ It is over expressed in many tumors like head and neck tumors, glioblastoma, lung, breast, ovaries and bladder. In the present study, we evaluated the expression of EGFR on different histopathological grades of MEC.

There are few studies present in literature showing expression of EGFR on MEC. In study conducted by Khiavi et al in 2012, out of 40 patients 2 were negative (4.3\%), 12 week positive (26.1\%) and 32 were strong positive (69.6\%). The EGFR expression was cytoplasmic that is contrary to present study, as it had both cytoplasmic and membranous expressions. In another study conducted by Al-Ani in 201214, out of seventeen patients all were EGFR immunopositive. No statistical significant correlation was seen among marker and grading systems. According to above mentioned study, 9 cases were weak positive and remaining 8 cases were strong positive. EGFR in this study showed membranous expression.

In 2010, Lujan et al conducted a study to check relation of EGFR expression in salivary glands MEC of high grade. ${ }^{15}$ Out of 42 cases, 34(79\%) cases were positive for protein expression. Expression of EGFR was high in high grade MEC, so it was more positive in aggressive tumors. They considered only continuous membranous staining of EGFR as strong positive. In contrast, we considered both cytoplasmic and membranous staining.

In a study conducted by Hoyek-Gebeily et al in 2007, in which they checked the prognostic significance of EGFR in MEC of the salivary gland, $75 \%$ of cases are positive for EGFR staining. ${ }^{16}$ They considered only membranous staining and found high expression of EGFR in high grade so have poor prognosis.

\section{Conclusion}

Expression of EGFR is strongly positive in high grade $M E C$ and in few cases of intermediate grade MEC. In low grade MEC, EGFR has both negative and week positive expression. EGFR showed both membranous and cytoplasmic expression.

\section{References}

1. Neville BW, Damm DD, Allen CM, Bouquot JE. Oral and Maxillofacial Pathology.3rded. Elsevier Health Sciences; 2015

2. Gill MS, Muzaffar S, Soomroi IN, Hussainy AS, Pervez S, Hasan SH. Morphological patterns of salivary glands tumors. J Pak Med Assos 2001; 51(10):343-46.

3. Bai S, Clubwala R, Alder E. Salivary mucoepidermoid carcinoma: A multi institutional review of 76 patients. Head and Neck Pathol 2001 ; 7(2): 105-112.

4. Hoyek - Gebeily J, Nehme E, Aftimos G, SaderGhorra C, Sargi Z, Haddad A. Prognostic significance of EGFR, P53 and E-cadherin in mucoepidermoid cancer of salivary glands. J Med Liban 2007; 55(2):83-8.

5. Auclair PL, Goode RK, Ellis GL. Mucoepidermoid carcinoma of intraoral salivary glands evaluation and application of grading criteria in 143 cases. Cancer. 1992;69(8):2021-30

6. Seshacharyulu $P$, Ponnusamy MP, Haridas D. Targeting the EGFR signaling pathway in cancer 
therapy. Expert Opinion Ther Targets 2012; 16(1):1531.

7. Han W, Wen H. Landscape of EGFR signaling network in human cancers: biology and therapeutic response in relation to receptor subcellular locations. Cancer Lett 2012; 318(2):124-134.

8. Pai SI, Weftra WH. Landscape of EGFR signaling network in human cancers: Biology and therapeutic response in relation to receptor subcellular locations. Cancer Left 2009; 318(2):124-134.

9. Shang J, Shui Y, Sheng L, Wang K, Hu Q, Wei Q. Epidermal growth factor receptor and human epidermal growth factor 2 expression in parotid mucoepidermoid carcinoma : possible implication for targeted therapy 2007; 19(2): 435-440.

10. Alos L, Castillo M, Nadal A, Caballero, Mardesa A, Mallofre C, Palacin A, Cardesa A. Adenosquamous carcinoma of head and neck: criteria for diagnosis in a study of 12 cases. Histopathology 2004; 44(6):570579.

11. Handra - Luca A, Lamas G, Bertrand JC, Fouret P. MUC1, MUC2, MUC4, MUC5AC expression in salivary gland mucoepidermoid carcinoma: diagnostic and prognostic implications. Am J surg pathol 2005; 29(7): 881-889.

12. Khiavi MM, Vosouughhosseini $S$, Saravani $S$, Halimi M. Immunohistochemical correlation of epidermal growth factor receptor and c-erb with histopathological grading of mucoepidermoid carcinoma. J. Can. Res. Therp 2012; 8(4): 586-590.

13. Klapper LN, Kirschbaum MH, Sela M, Yarden Y. Biochemical and clinical implications of ErbB/HER signaling network of growth factor receptors. Adv Cancer Res 1999; 77: 25-79.

14. Al- Ani, S A, Abdullah BH. Evaluation of epidermoid growth factor receptor (EGFR), proliferation (Ki- 67) and apoptosis (P53) in salivary mucoepidermoid carcinoma in relation to tumor grade. J Bagh College Dentistry 2012; 24(2): 43-47.

15. Lujan B, Hakim S, Moyano S, Nadal A, Caballero M, Diaz A, Valera A. Activation of the EGFR/ERK pathway in high-grade mucoepidermoid carcinoma of the salivary glands. British Journal of Cancer 2010; 103(4)
:510-516. 